\title{
Application and interpretation of an interferon-gamma release assay: Results of an audit in a Canadian centre
}

\author{
Sopharat Vat $M D^{1}$, Marc Ghannoum $\mathrm{MD}^{2}$, Pierre Laflamme $\mathrm{MD}^{3}$, Mario Dugas $\mathrm{MD}^{4}$, \\ Manon Labrecque $\mathrm{MD}^{4}$, Valéry Lavergne $\mathrm{MD}^{3}$
}

S Vat, M Ghannoum, P Laflamme, M Dugas, M Labrecque, $\mathrm{V}$ Lavergne. Application and interpretation of an interferongamma release assay: Results of an audit in a Canadian centre. J Infect Dis Med Microbiol 2012;23(4):183-186.

BACKGROUND: Interferon-gamma release assays (IGRAs) are newly approved for diagnosing latent tuberculosis infection (LTBI). An internal audit was conducted to review the use of a newly implemented IGRA at the Hôpital du Sacré-Coeur de Montréal (Montréal, Québec) to evaluate its concordance with Canadian recommendations and its implication on diagnosis.

METHODS: From April 2007 to January 2009, all Quantiferon TB Gold In-Tube (QFT, Cellestis inc, USA) tests performed in at the Hoppital $d u$ Sacré-Coeur de Montréal were retrieved. Strategies used to investigate LTBI and clinical interpretation of test results were compared with the local algorithm, which is derived from the current national guidelines.

RESULTS: A total of 200 patients tested with QFT were included in the analysis. LTBI investigation and QFT testing were considered to be appropriate in $87.5 \%$ and $66.5 \%$ of patients, respectively. Overall, 67 QFT tests were performed inappropriately; 25 were performed when a LTBI investigation was not indicated and 42 were performed whe LTBI interpretation was possible with the result of the tuberculin skin test alone. Among the 175 patients investigated appropriately for LTBI, 49 QFT tests (28\%) were interpreted incorrectly; 32 patients (at high risk of developing active tuberculosis) had a positive tuberculin skin test and a negative QFT result wrongly interpreted as being negative for LTBI and 13 patients should have undergone further LTBI investigations.

CONCLUSION: Globally, the present study revealed that there are discrepancies on how the IGRA was employed and interpreted in a Montreal hospital and that strict compliance to the guidelines could significantly reduce errors in interpretation.

Key Words: Canadian guidelines; Interferon-gamma release assays (IGRA); Internal audit; Quality assurance; Quantiferon TB Gold In-Tube; Tuberculosis

$\mathrm{T}$ uberculosis (TB) infection remains a major public health issue worldwide. Global efforts are focused on the prevention, diagnosis, screening and treatment of TB $(1,2)$. Identification and treatment of latent TB infection (LTBI) are among the preferred strategies to control dissemination of the disease (3). The WHO published guiding principles for national TB programs (1). According to the Canadian Tuberculosis Standards, testing for LTBI is indicated for infected patients at high risk of developing the disease (4). Until recently, tuberculin skin testing (TST) was the only available test for diagnosis of LTBI. Interferon-gamma release assays (IGRAs) are now approved as complementary tools for diagnosing Mycobacterium tuberculosis infection (4-8).

Despite the lack of a gold standard for diagnosis of LTBI, and despite the understudied predictive value of IGRAs (9), the Canadian Tuberculosis Committee issued recommendations for the use of IGRAs based on best available scientific evidence, national TB incidence and Bacillus Calmette-Guérin (BCG) vaccination prevalence $(5,10,11)$.

\section{L'application et l'interprétation d'un test de libération d'interféron gamma : résultats d'une vérification dans un centre canadien}

HISTORIQUE : Les tests de libération d'interféron gamma (TLIG) ont récemment été approuvés pour diagnostiquer une infection tuberculeuse latente (ITBL). Une vérification interne a été organisée pour examiner l'utilisation d'un nouveau TLIG à l'Hôpital du Sacré-Cœur de Montréal (Montréal, Québec) ainsi que pour en évaluer la concordance avec les recommandations canadiennes et les conséquences sur le diagnostic.

MÉTHODOLOGIE : D'avril 2007 à janvier 2009, les chercheurs ont extrait tous les tests Quantiferon TB Gold In-Tube (QFT) effectués à leur centre. Ils ont comparé les stratégies utilisées pour évaluer l'ITBL et l'interprétation clinique des résultats des tests avec leur algorithme local, dérivé des lignes directrices nationales à jour.

RÉSULTATS : Au total, 200 patients ayant subi le test QFT ont participé à l'analyse. L'examen de l'ITBL et le test QFT ont été considérés comme convenables chez $87,5 \%$ et $66,5 \%$ des patients, respectivement. Dans l'ensemble, 67 tests QFT avaient été mal exécutés, soit 25 lorsque l'examen de l'ITBL n'était pas indiqué et 42 lorsqu'il était possible d'interpréter l'ITBL grâce aux seuls résultats du test cutané à la tuberculine. Chez les 175 patients ayant subi des examens convenables de l'ITBL, 49 tests QFT (28\%) avaient été mal interprétés. En effet, 32 patients (très vulnérables à une tuberculose active) présentaient un test cutané à la tuberculine positif et un résultat négatif du test QFT interprété à tort comme négatif à l'ITBL, tandis que 13 patients auraient dû subir des examens plus approfondis de l'ITBL.

CONCLUSION : Globalement, la présente étude a révélé des divergences dans l'utilisation du TLIG au centre et établi qu'un respect rigoureux des lignes directrices pourrait réduire considérablement les erreurs d'interprétation.

\footnotetext{
${ }^{1}$ Université de Montréal; ${ }^{2}$ Département de médecine interne, Hôpital de Verdun; ${ }^{3}$ Département de microbiologie médicale et infectiologie;

${ }^{4}$ Département de pneumologie, Hôpital du Sacré-Coeur de Montréal, Montréal, Québec

Correspondence: Dr Valéry Lavergne, Département de microbiologie médicale et infectiologie, Hôpital du Sacré-Coeur de Montréal, 5400 Boulevard

Gouin Ouest, Montréal, Québec H4J 1C5. Telephone 514-338-2222 ext 7221, fax 514-338-3517, e-mail valerylavergne @gmail.com
} 


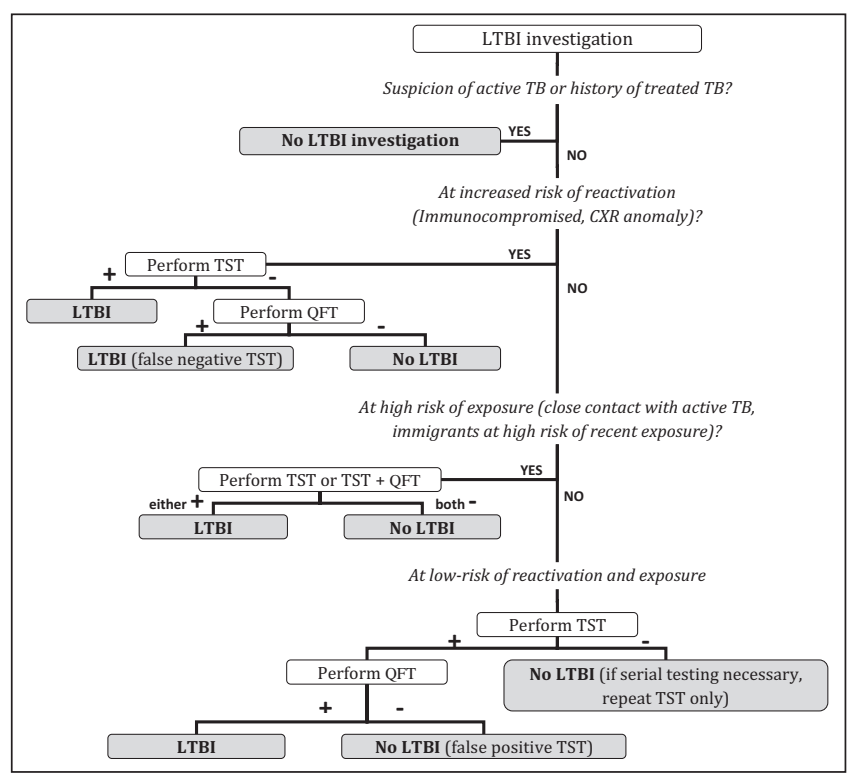

Figure 1) Local algorithm of latent tuberculosis (TB) infection (LTBI) investigation (derived from Canadian guidelines). CXR Chest x-ray; QFT Quantiferon TB Gold In-Tube (Cellestis Inc, USA); TST Tuberculin skin testing

staff members of the infectious diseases and respiratory departments. Concomitantly, a local algorithm, derived from the Canadian Tuberculosis Standards (4) and the Canadian Tuberculosis Committee position statement (10) was constructed and proposed (Figure 1). There was no restriction among physicians on who could order the test and in what specific context it could be prescribed.

From April 2007 to January 2009, all QFT tests performed in the institution were retrieved from the microbiology data bank. Patients without a medical record in the institution were excluded from the analysis. Approval from the institution's ethics committee was obtained before conducting the audit. Demographic and clinical characteristics of patients were recorded from medical charts using a standardized form.

\section{Definitions}

High TB incidence countries were defined as having a threeyear average rate of sputum smear-positive pulmonary TB $\geq 15$ per 100,000 population (1). Patients considered at high risk of reactivation (according to Canadian Tuberculosis Standards) included those being immunosuppressed (excluding cigarette smoking, diabetes and being underweight as single factors) and demonstrating radiographical evidence of past untreated TB (excluding the presence of granuloma alone) (4). TST conversion was confirmed only after excluding a booster effect. BCG vaccination status was based on vaccination certificate and/or on patient recall. A decision was considered to be appropriate if it followed the local algorithm.

\section{QFT procedure}

The QFT procedure was protocolized according to the manufacturer's monograph (14). All critical steps for collecting and handling samples were thoroughly explained to phlebotomists, which included a sampling volume of $\geq 1 \mathrm{~mL}$ in all three specialized blood collection tubes (nil control tube, $\mathrm{TB}$ antigen tube and mitogen control tube), tube inversion for $5 \mathrm{~s}$ immediately after collection and immediate transport to the laboratory at room temperature. Technicians rejected all inadequate specimens arriving to the laboratory. Accepted specimens were incubated as soon as possible, and within $16 \mathrm{~h}$ of collection. Following a $16 \mathrm{~h}$ to $24 \mathrm{~h}$ incubation period and centrifugation, plasma samples were stored at $4^{\circ} \mathrm{C}$ for a two- to four-week period, until further testing for quantification of interferon-gamma using ELISA. Data analysis and result interpretation were done using the Quantiferon-TB Gold IT Analysis software.
TABLE 1

Patient characteristics and tuberculin skin testing (TST) indication

\begin{tabular}{lc}
\hline Patient characteristics & $\begin{array}{c}\text { Patients } \\
\text { (n=200) }\end{array}$ \\
\hline Age, years, mean (range) & $45(18-91)$ \\
Male sex & $77(38.5)$ \\
Foreign born & $128(64.0)$ \\
Bacillus Calmette-Guérin vaccination & \\
Confirmed & $94(47.0)$ \\
Probable & $40(20.0)$ \\
Tuberculin skin testing indication & \\
Inappropriate tuberculin skin testing use & \\
$\quad$ High index of suspicion or documented active TB & $22(11.0)$ \\
$\quad$ Screening in patients with history of treated TB & $3(1.5)$ \\
Appropriate tuberculin skin testing use & \\
$\quad$ Immunocompromised individuals & $47(23.5)$ \\
Individuals with radiographic evidence of old, untreated TB & $1(0.5)$ \\
Contact investigation & $25(12.5)$ \\
$\quad$ Screening of immigrants at high risk of recent exposure & $21(10.5)$ \\
Health care workers (baseline and serial testing) & $64(32.0)$ \\
Screening in patients with a low risk of exposure and & $5(2.5)$ \\
$\quad$ a low-risk of reactivation (pre-employment) & \\
Absence of TST (only OFT test was performed) & $12(6.0)$
\end{tabular}

Absence of TST (only QFT test was performed)

$12(6.0)$

Data presented as $n$ (\%) unless otherwise indicated. TB Tuberculosis; QFT Quantiferon TB Gold In-Tube (Cellestis Inc, USA)

Patient characteristics

\section{RESULTS}

From April 2007 to January 2009, a total of 207 QFT tests from 200 patients were performed (63 positive, 129 negative and 15 indeterminate results). As shown in Table 1, 128 patients were born in a foreign country. One hundred thirty-four patients had previous BCG vaccination. A TST was performed in 188 patients, 163 of which followed the algorithm. Appropriate screening indications with TST included health care workers $(32.0 \%)$, immunocompromised patients $(23.5 \%)$, individuals in the context of a contact investigation $(12.5 \%)$, immigrants at high-risk of recent exposure $(10.5 \%)$, pre-employment $(2.5 \%)$ and individual with radiographic evidence of old TB $(0.5 \%)$. LTBI investigation was then considered inappropriate in $12.5 \%$ of patients. The median time interval between TST and QFT testing was 42 days (interquartile range 14 to 114 days).

\section{Indications for QFT testing}

According to the algorithm, QFT testing was considered to be appropriate in only $66.5 \%$ of patients (Table 2 ). QFT testing was appropriately used in 133 patients, either as a two-step approach (in 27 patients at increased risk of reactivation after a negative TST and 67 patients at low risk of developing the disease after positive TST) or as simultaneous TST/QFT testing in 39 patients at high risk of exposure.

Overall, 67 QFT tests were ordered inappropriately. Twenty-five QFT tests were performed when LTBI should not have been investigated (high suspicion of active TB or previous history of treated TB). When investigation for LTBI was indicated, 42 QFT tests were performed when LTBI interpretation was possible with the result of the TST alone: 21 QFT tests in a context of increased risk of reactivation after a positive TST, two in low-risk TB exposure after a negative TST and seven in health care workers after TST conversion. Finally, in 12 patients, a QFT test was performed without a previously administered TST, all in patients at increased risk of developing active TB.

\section{Interpretation of TST/QFT results}

Among the 175 patients investigated appropriately for LTBI, 126 (72\%) had correct TST/QFT interpretations, while 49 patients $(28 \%)$ had interpretative TST/QFT errors (Table 3). Thirty-two of these errors occurred when clinicians falsely interpreted a positive $(+) \mathrm{TST} /$ negative 
TABLE 2

Indications of Quantiferon TB Gold In-Tube* (QFT) testing according to local algorithm

\begin{tabular}{|c|c|}
\hline Variables & $\begin{array}{l}\text { Patients } \\
(\mathrm{n}=200)\end{array}$ \\
\hline \multicolumn{2}{|l|}{ Inappropriate LTBI investigation } \\
\hline High index of suspicion or documented active TB & $22(11.0)$ \\
\hline History of treated TB & $3(1.5)$ \\
\hline \multicolumn{2}{|l|}{ Appropriate LTBI investigation } \\
\hline \multicolumn{2}{|l|}{ Inappropriate QFT use } \\
\hline $\begin{array}{l}\text { TST+ in patients at increased risk of reactivation (immunosuppression } \\
\text { or radiographical evidence of past untreated TB) }\end{array}$ & n $21(10.5)$ \\
\hline $\begin{array}{l}\text { Performed alone in patients at increased risk of developing } \\
\text { active TB }\end{array}$ & $12(6.0)$ \\
\hline TST- in patients following contact at low risk of exposure & $2(1.0)$ \\
\hline TST conversion in health care workers & $7(3.5)$ \\
\hline \multicolumn{2}{|l|}{ Appropriate QFT use } \\
\hline $\begin{array}{l}\text { TST- in patients at increased risk of reactivation } \\
\text { (immunosuppression or radiographic evidence of old untreated TB) }\end{array}$ & $27(13.5)$ \\
\hline $\begin{array}{l}\text { TST+ in screening of patients with close contact at high risk of } \\
\text { exposure }\end{array}$ & $18(9.0)$ \\
\hline TST+ in screening of immigrants at high-risk of recent exposure & $21(10.5)$ \\
\hline TST+ patients following contact at low risk of exposure & $5(2.5)$ \\
\hline TST + at baseline in health care workers at low risk of developing TB & $57(28.5)$ \\
\hline TST+ patients at low risk of developing the disease & $5(2.5)$ \\
\hline
\end{tabular}

Data presented as $n$ (\%). *Celletis Inc, USA. LTBI Latent tuberculosis infection; - Negative; + Positive; TB Tuberculosis; TST Tuberculin skin testing

(-) QFT result as being negative for LTBI in patients at a high risk of developing active TB ( 22 at high-risk exposure, seven at increased risk of reactivation and three health care workers with TST conversion). Three patients at low risk of developing active TB had a +TST/-QFT result and were wrongly diagnosed as having LTBI (instead of being regarded as having a false +TST result). One patient at low risk of developing the disease had a $+\mathrm{TST} /+\mathrm{QFT}$ result and was not diagnosed as having LTBI. Thirteen QFT results (7.4\%) should have prompted further LTBI investigation, which was not ultimately done; in 10 cases, a TST should have been performed after a -QFT or indeterminate QFT result, while three indeterminate QFTs should have been repeated.

\section{DISCUSSION}

The use of IGRAs has grown considerably in the diagnosis of LTBI during the past decade. IGRAs have promising advantages over the conventional TST, which include a single medical visit, fewer technical errors, increased specificity in patients with previous BCG vaccination and possible better sensitivity in immunocompromised patients $(5,6,15)$. Nevertheless, according to a recent meta-analysis, neither IGRAs nor the TST have high accuracy for the prediction of active TB, although use of IGRAs in some populations may reduce the number of people considered for preventive treatment (9).

Most national TB guidelines now include IGRA among the investigative tools of choice and provide valuable information on their clinical use in various settings (5-8). However, there remains considerable confusion about the applicability of such guidelines; they have marked heterogeneity due, among other reasons, to the variable local availability of QFT testing, BCG vaccination prevalence, national TB incidence and immigration profile (8). Furthermore, the majority of these guidelines have certain methodological flaws (level of evidence is not always graded and conflicts of interests not disclosed). Finally, clinicians who are not familiar with current guidelines may find them complex and confusing.

Until now, performance indicators evaluating the adequacy of IGRAs use have been seldom studied $(16,17)$. An internal audit was performed in our centre to identify the added value and shortcomings of the use of the IGRA when applied via a standardized algorithm derived from Canadian guidelines.
TABLE 3 Interpretation of tuberculin skin testing (TST)/Quantiferon TB Gold In-Tube* (QFT) results

\begin{tabular}{|c|c|c|c|}
\hline Variables & $\begin{array}{l}\text { QFT } \\
\text { result }\end{array}$ & $\begin{array}{l}\text { Correct action/ } \\
\text { interpretation }\end{array}$ & $\begin{array}{l}\text { Incorrect action/ } \\
\text { interpretation } \\
\text { errors }\end{array}$ \\
\hline \multicolumn{4}{|c|}{ Inappropriate LTBI investigation $(n=25)$} \\
\hline $\begin{array}{l}\text { High index of suspicion or } \\
\text { documented active TB }\end{array}$ & Any QFT & $\begin{array}{l}\text { Rule out active } \\
\text { TB }(n=22)\end{array}$ & None \\
\hline History of treated TB & Any QFT & $\begin{array}{l}\text { Rule out active } \\
\text { TB or no LTBI } \\
(n=3)\end{array}$ & None \\
\hline \multicolumn{4}{|l|}{ Inappropriate QFT use $(n=42)$} \\
\hline $\begin{array}{l}\text { TST+ in patients at increased } \\
\text { risk of reactivation } \\
\text { (immunosuppression or } \\
\text { radiographic evidence of old } \\
\text { untreated TB) }\end{array}$ & Any QFT & LTBI (n=14) & $\begin{array}{l}\text { No LTBI when } \\
\text { QFT- }(n=7)\end{array}$ \\
\hline TST not performed in patients & QFT+ & LTBI $(n=2)$ & None \\
\hline $\begin{array}{l}\text { at increased risk of } \\
\text { developing } \\
\text { active TB }\end{array}$ & $\begin{array}{l}\text { QFT- or } \\
\text { ind }\end{array}$ & $\begin{array}{l}\text { Proceed to TST } \\
\qquad(\mathrm{n}=0)\end{array}$ & $\begin{array}{l}\text { Incomplete } \\
\text { investigation } \\
(n=10)\end{array}$ \\
\hline $\begin{array}{l}\text { TST- in patients with contact } \\
\text { after low risk TB exposure }\end{array}$ & QFT- & No LTBI $(n=2)$ & None \\
\hline $\begin{array}{l}\text { TST conversion in health care } \\
\text { workers }\end{array}$ & Any QFT & LTBI $(n=4)$ & $\begin{array}{l}\text { No LTBI when } \\
\text { QFT- }(n=3)\end{array}$ \\
\hline \multicolumn{4}{|l|}{ Appropriate QFT use $(n=133$ ) } \\
\hline \multirow[t]{3}{*}{$\begin{array}{l}\text { TST- in patients at increased } \\
\text { risk of reactivation }\end{array}$} & QFT+ & $\begin{array}{l}\text { False negative } \\
\text { TST }(n=5)\end{array}$ & None \\
\hline & QFT- & No LTBI (n=17) & None \\
\hline & QFT ind & $\begin{array}{l}\text { Repeat testing } \\
(\mathrm{n}=2)\end{array}$ & $\begin{array}{l}\text { Incomplete } \\
\text { investigation } \\
(\mathrm{n}=3)\end{array}$ \\
\hline $\begin{array}{l}\text { TST + in screening of patients } \\
\text { with close contact or } \\
\text { immigrants with a high risk } \\
\text { of recent exposure }\end{array}$ & Any QFT & LTBI (n=17) & $\begin{array}{l}\text { No LTBI when } \\
\text { QFT- }(n=22)\end{array}$ \\
\hline \multirow{2}{*}{$\begin{array}{l}\text { TST+ in individuals at low risk } \\
\text { of developing the disease } \\
\text { (contact at low risk exposure, } \\
\text { health care workers, other } \\
\text { patients at low risk) }\end{array}$} & QFT+ & LTBI (n=18) & No LTBI $(n=1)$ \\
\hline & QFT- & $\begin{array}{l}\text { False positive } \\
\text { TST }(n=45)\end{array}$ & LTBI (n=3) \\
\hline
\end{tabular}

${ }^{*}$ Celletis Inc, USA. ind Indeterminate; LTBI Latent tuberculosis infection; - Negative; + Positive; TB Tuberculosis; TST Tuberculin skin testing

The present study revealed that there are significant discrepancies on how IGRAs are employed in our centre; overall, the use of QFT testing correctly followed the 2008 Canadian Tuberculosis Committee position statement in two-thirds of cases, which is better than the $24 \%$ obtained in a previous United Kingdom audit (16). When a clinical situation warranted LTBI investigation, the use of QFT testing was appropriate in $76 \%$ of cases. The most common error was ordering a QFT test following a TST + result in patients at increased risk of reactivation; in each of these situations, a diagnosis of LTBI was possible without further QFT testing.

There was one context in the local algorithm in which the appropriate investigation was ambiguous, ie, clinicians had the option of either performing a TST and/or a combination of TST and QFT for patients at high risk of TB exposure (close contact with active TB or immigrants with high risk of recent exposure). Although both options are considered to be acceptable according to Canadian guidelines $(5,11)$, our experience suggests that interpretation was misguided in the majority of cases; in 22 patients, a TST+/QFT - result was interpreted as "no LTBI", although the opposite interpretation was warranted, based on 
the positive TST result. Considering that these patients are at high risk of recent TB exposure, these errors can have a major health care impact and should be addressed in further guideline versions.

Overall, there are many potential reasons to explain why clinician's behaviour regarding QFT testing diverged from accepted recommendations:

1) New diagnostic tools stimulate interest among clinicians who are eager to measure a test's performance within their own practice. For example, QFT tests were frequently used in active TB cases, although IGRAs have no recognized value for active TB diagnosis and are not currently recommended in adults (18).

2) Physicians wrongly assume that QFT, because of its higher specificity, is an appropriate confirmation test after a TST+ result, although this is only recommended to rule out a false TST + result in specific situations (eg, positive TST in patients at relatively low risk of developing the disease). In most other contexts, a TST+ result alone is sufficient to pose a diagnosis of LTBI. The test's predictive value, instead of its specificity, is a superior measure of its validity because it accounts for disease prevalence.

3) In some cases, QFT was done alone, without a TST being given first. Again, this suggests that some clinicians believe QFT to be a superior test to TST, although this statement remains to be supported by current evidence. Alternatively, the use of QFT alone could also be explained by the notable differences between national guidelines; for example, the 2005 American guidelines stipulate that QFT can be used "in all circumstances in which the TST is used, including contact investigations, evaluation of recent immigrants who have had BCG vaccination, and TB screening of health-care workers" and "can be used in place of (and not in addition to) the TST" (19). This contrasts with Canadian recommendations (11). Physicians who rely more heavily on American-based medical literature may, therefore, have distinctly different approaches than their colleagues who follow Canadian recommendations.

4) Physicians sometimes delay treatment by ordering an unnecessary QFT. For example, BCG-vaccinated patients recently emigrated from endemic regions and at high risk of recent exposure with a positive

\section{REFERENCES}

1. World Health Organization. Tuberculosis (TB), 2011. <www.who. int/tb/en> (Accessed August 31, 2011).

2. Public Health Agency of Canada. Tuberculosis Prevention and Control, 2011. <www.publichealth.gc.ca/tuberculosis> (Accessed August 31,2011) .

3. Horsburgh CR Jr. Priorities for the treatment of latent tuberculosis infection in the United States. N Engl J Med 2004;350:2060-7.

4. Public Health Agency of Canada and Canadian Lung Association. Long R, Ellis E, editors. Canadian tuberculosis standards, 6th edn. Ottawa ON: Her Majesty the Queen in Right of Canada, represented by the Minister of Health, 2007: 3 .

5. Public Health Agency of Canada. Recommendations on interferon gamma release assays for the diagnosis of latent tuberculosis Infection - 2010 Update. Can Commun Dis Rep 2010;36(ACS-5):1-22.

6. Mazurek GH, Jereb J, Vernon A, LoBue P, Goldberg S, Castro K. Updated guidelines for using interferon gamma release assays to detect Mycobacterium tuberculosis infection - United States, 2010. MMWR Recomm Rep 2010;59(RR-5):1-25.

7. National Institute for Health and Clinical Excellence. Tuberculosis: Clinical diagnosis and management of tuberculosis, and measures for its prevention and control. London, 2006.

8. Denkinger CM, Dheda K, Pai M. Guidelines on interferon-gamma release assays for tuberculosis infection: Concordance, discordance or confusion? Clin Microbiol Infect 2011;17:806-14.

9. Rangaka MX, Wilkinson KA, Glynn JR, et al. Predictive value of interferon-gamma release assays for incident active tuberculosis: A systematic review and meta-analysis. Lancet Infect Dis 2012;12:45-55.

10. Public Health Agency of Canada. Interferon gamma release assays for latent tuberculosis infection. An Advisory Committee Statement (ACS). Can Commun Dis Rep 2007;33(ACS-10):1-18.

11. Public Health Agency of Canada. Updated recommendations on interferon gamma release assays for latent tuberculosis infection. An
TST result may contest treatment and convince their physicians to undergo QFT testing for confirmation. While this strategy is reasonable for low-risk patients, this should not apply to high-risk patients who should be treated. Risk stratification should be evaluated by the pretest clinical setting and not by the result of a QFT.

To improve compliance and uniformity, national efforts should be made to disseminate the summary of the recommendations, via educative tools, if necessary. On a local level, restricted access to QFT or requiring physicians to indicate results of previous TST could be implemented. Further regular audits will permit assessment of the efficacy of these measures.

The present study gave insight into the behaviour of physicians with regard to QFT testing. Our results found that clinicians often use the QFT outside of its recommended scope and occasionally erred in its interpretation, especially when a QFT was not necessary. This potentially prejudices patients needing TB treatment. Until we can better quantify the predictive value of IGRAs in different specific contexts, it is perhaps prudent to use them in conjunction with the TST, as currently recommended by Canadian guidelines $(5,9)$. To improve understanding of IGRA use, it may be worthwhile to employ performance indicators such as those described in the present study. Future versions of guidelines could then target sections that appear to be less well assimilated and improve the clarity of misunderstood statements, especially when QFT interpretation leads to potentially hazardous situations.

\section{CONCLUSION}

Canadian recommendations on LTBI investigation and QFT testing were followed inconsistently among physicians in our centre, with potentially serious management consequences. Aside from the ambiguous case of high-risk exposure, where optimal investigation remains unclear, strict compliance to the guidelines should significantly reduce errors in interpretation. The present audit was followed by local targeted corrective interventions and will be reconvened in 2012 .

DISCLOSURE: The authors have no financial disclosures or conflicts of interest to declare.

Advisory Committee Statement (ACS). Can Commun Dis Rep 2008;34(ACS-6):1-13.

12. Ibrahim JE. Performance indicators from all perspectives. Int J Qual Health Care 2001;13:431-2.

13. de Vos M, Graafmans W, Kooistra M, Meijboom B, Van Der Voort P, Westert G. Using quality indicators to improve hospital care: A review of the literature. Int J Qual Health Care 2009;21:119-29.

14. QuantiFERON-TB Gold (In-Tube Method). Cellestis. 2006:1-36. $<$ www.cellestis.com/IRM/Company/ShowPage.aspx?CPID=1171> Accessed 20 September 2011.

15. Cattamanchi A, Smith R, Steingart KR, et al. Interferon-gamma release assays for the diagnosis of latent tuberculosis infection in HIV-infected individuals: A systematic review and meta-analysis. J Acquir Immune Defic Syndr 2011;56:230-8.

16. Ijeh C, Raza MM, Bhattacharya M, Mukherjee R. Use of interferongamma assay in the United Kingdom: Compliance with national guidance. 20th European Congress of Clinical Microbiology and Infectious Diseases. Vienna, April 10 to 13, 2010.

17. Mohandas K, Cunniffe JG. Audit of NICE guidelines for tuberculosis: Laboratory diagnosis and infection control aspects. The Bulletin of the Royal College of Pathologists. 2009;146:162-5. $<$ www.rcpath.org/Resources/RCPath/Migrated\%20Resources/ Documents/A/auditniceguidelinesapr09.pdf $>$ (Accessed 10 October 2011).

18. Metcalfe JZ, Everett CK, Steingart KR, et al. Interferon-gamma release assays for active pulmonary tuberculosis diagnosis in adults in low- and middle-income countries: Systematic review and metaanalysis. J Infect Dis 2011;204 (Suppl 4):S1120-9.

19. Mazurek GH, Jereb J, Lobue P, Iademarco MF, Metchock B, Vernon A. Guidelines for using the QuantiFERON-TB Gold test for detecting Mycobacterium tuberculosis infection, United States. MMWR Recomm Rep. 2005;54(RR-15):49-55. 


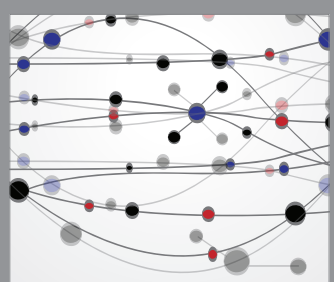

The Scientific World Journal
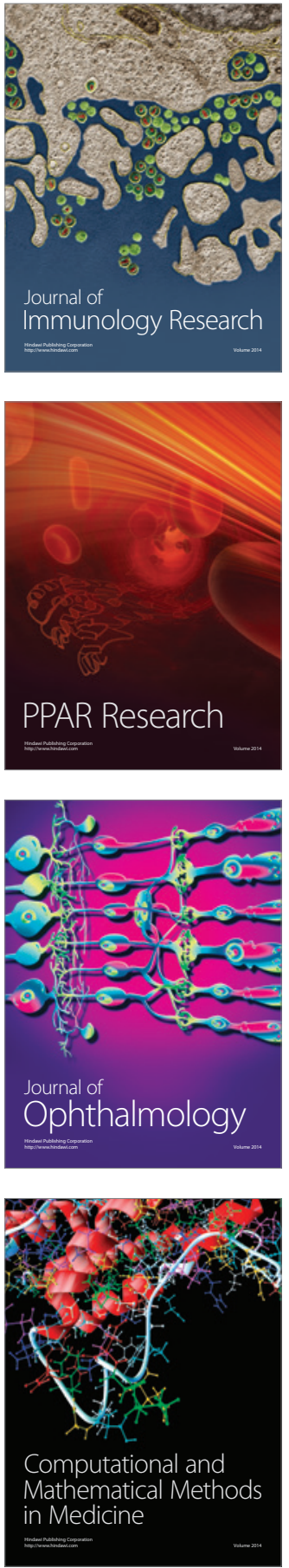

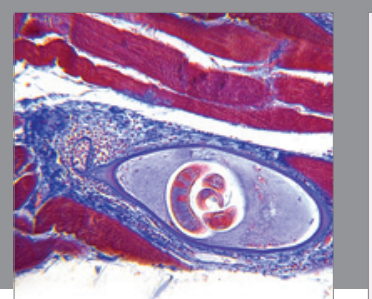

Gastroenterology Research and Practice

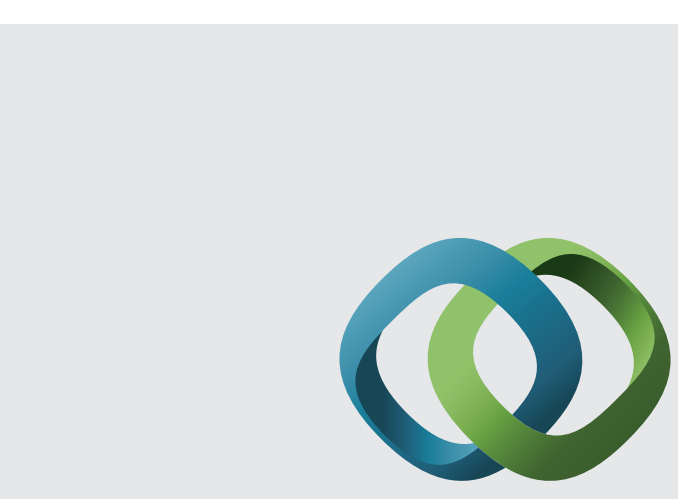

\section{Hindawi}

Submit your manuscripts at

http://www.hindawi.com
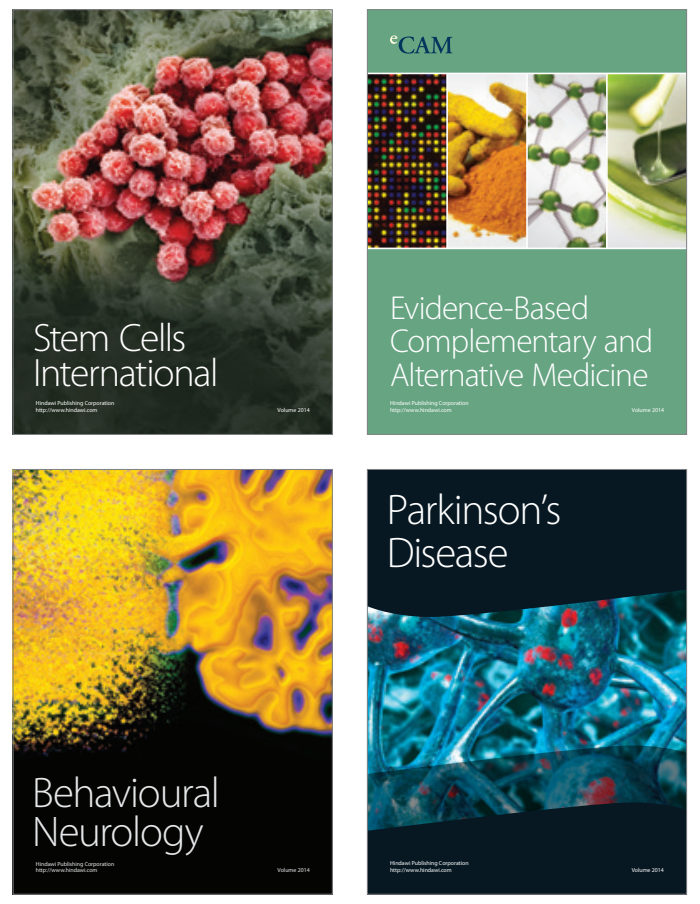
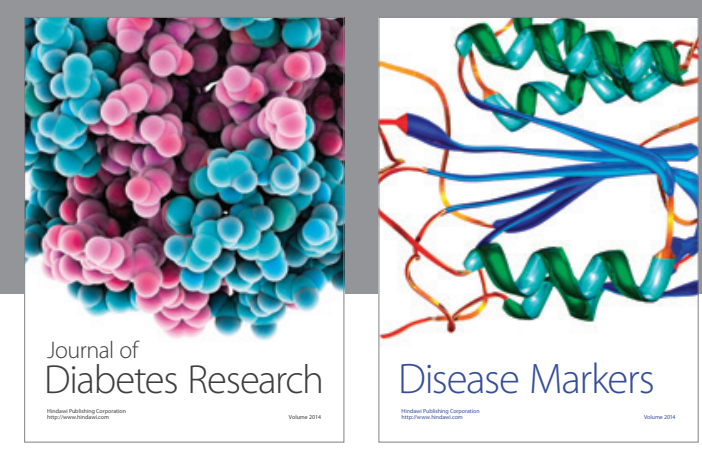

Disease Markers
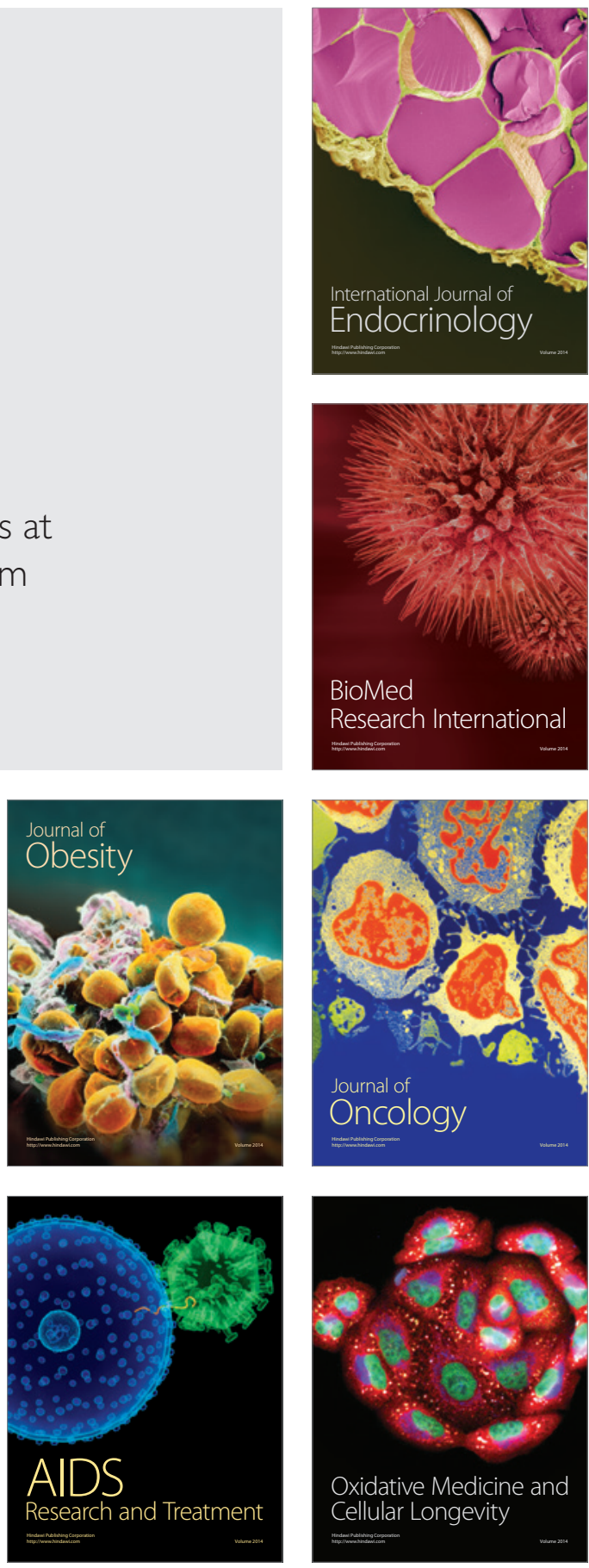